\title{
Evaluation of direct shear strength of compacted bentonite having pore-water pressure
}

\author{
Tomoyoshi Nishimura ${ }^{1, *}$, and Masaaki Fukaya ${ }^{2}$ \\ ${ }^{1}$ Department of Civil Engineering, Ashikaga University, Tochigi, Japan \\ ${ }^{2}$ Nuclear Waste Technology Department, OBAYASHI CORPORATION, Tokyo, Japan
}

\begin{abstract}
Safety of great deep repository design has been investigated for high-level radioactive waste disposal system in several countries such as Belgium, Canada, China, France, Germany, Japan, Sweden and Switzerland. The repository of the disposal is in most cases based on the concept of a multi-barrier system using the host rock barrier formation and a man-made barrier formation. The man-made barrier consists of high expansive bentonite. Thermal-hydro-mechanical behaviour simulation models were developed, including some parameters described by experimental works. The complex phenomena due to the transition into saturation and chemical reactions at the bentonite barrier system have been explained. This study focused on direct shear strength for compacted bentonite related to some factors induced by uncertainty problems such as hydration effect and pore-water pressure. Measured shear strength properties of compacted bentonite had been determined at high suction values. Also, it is clear that there is some influence of direct shear speed on direct shear strength both under unsaturated-saturated conditions. A modified direct shear apparatus was used in this study to observe changes in shear strength with increments of pore-water pressures.
\end{abstract}

\section{Introduction}

Safety of great deep repository design has been investigated for high-level radioactive waste disposal system in several countries [1,2] such as Belgium, Canada, China, France, Germany, Japan, Sweden and Switzerland. The repository of the disposal is in most cases based on the aspect of a multi-barrier system such as the host rock barrier formation and man-made barrier formation. The man-made barrier system consists of high expansive bentonite [3]. Hydro-mechanical-thermal simulation analysis models [4] were developed, including some parameters described by experimental works. The complex phenomena associated with the transition into saturation and chemical reaction $[5,6]$ at bentonite barrier system have been explained. The mathematical models for a multipurpose application have been suggested by many researchers, and indicate many interesting phenomena of barrier system for long periods. The many mathematical models require lots of experimental test results to establish correct predictions for thermal-hydro-mechanical behaviour.

It is essential for the interpretation of phenomena in the barrier system to estimate the parameters regarding dominant factors [7-9] such as thermal, hydration, mechanical and chemical. Otherwise, it is difficult that the obtained simulation results are accurate. Many researches and environmental engineers noticed that hydration effects cause uncertainty in the behaviour of unsaturated and compacted bentonites.
This study focused on the shear strength in a direct shear apparatus for compacted bentonite related to some factors induced by uncertainty problems [10-12] such as hydration effect, gas pressure and pore-water pressure. Shear strength properties were mentioned in the high suction ranges [11]. Also, the influence of shear speed on direct shear strength was considered both in unsaturated-saturated conditions [12]. A modified direct shear apparatus was useful to study the effect of porewater pressure in saturated bentonite $[11,12]$.

This testing program focused on various pore-water pressures in saturated bentonite with different vertical stresses. Changes of direct shear strength were measured induced by increasing pore-water pressure for saturated bentonite. Even if the difference between vertical stress and supplied pore-water pressure was constant, production of pore-water pressure induced the direct shear strength to increase. Obtained relationship between pore-water pressures and direct shear strength will be obviously useful the estimation of bentonite barrier after long-time.

\section{Soil material and testing programs}

\subsection{Soil material}

Sodium bentonite (Kunigel V1) taken in Japan was used for direct shear test and chemical component $\mathrm{SiO}_{2}$ of the material occupied $62 \%$. The bentonite has been

Corresponding author: tomo@ ashitech.ac.jp 
widely used for investigation of mechanical properties of a high-level radioactive waste disposal barrier system in Japan. Some laboratory research institutes had been published several important data sets obtained from physical properties testing and hydro-mechanical testing. Then, the material specimen was employed as one of the reference materials and had a comparison to other swelling clay materials in the outside. Addition, Kunigel $\mathrm{V} 1$ is one of the representative expansive materials in Sodium material category.

A sand was mixed with the bentonite with uniform grain size distribution as indicated from grain size test and evaluated to classify as siliceous sand. Iitoyo sand \#3 was recognized as the registered trademark. Maximum soil particle was regulated to less than 2.0 $\mathrm{mm}$. Both bentonite and sand subjected to supply water to confirm the water content of $5.9 \%$ using a spray.

Previously, the soil-water characteristic curve SWCC was described at high suction ranges in terms of the relationship between suction and water content in Fig. 1. The SWCC is one of the significant physical properties that had useful in establishing mathematical simulation for hydro-mechanical behaviour. Changing of soil moisture through drying process on high suction ranges (i.e. suction more than $1.0 \mathrm{MPa}$ ) was very interesting. The SWCC was measured using vapour pressure technique using glass desiccator.

The range of temperature was from $20^{\circ} \mathrm{C}$ and $60^{\circ} \mathrm{C}$, indicating that the influence of temperature was slight. The slope of decrement of water content was seemed to be different at suction of $39 \mathrm{MPa}$ as a boundary with two portions that were expressed using two straight lines.

Bentonite with sand mixture was statically compacted in the shear box. The specimen corresponding suction of $105 \mathrm{MPa}$ had a dry density of $1.60 \mathrm{~g} / \mathrm{cm}^{3}$ which a diameter of $6.00 \mathrm{~cm}$ and a height of $2.50 \mathrm{~cm}$.

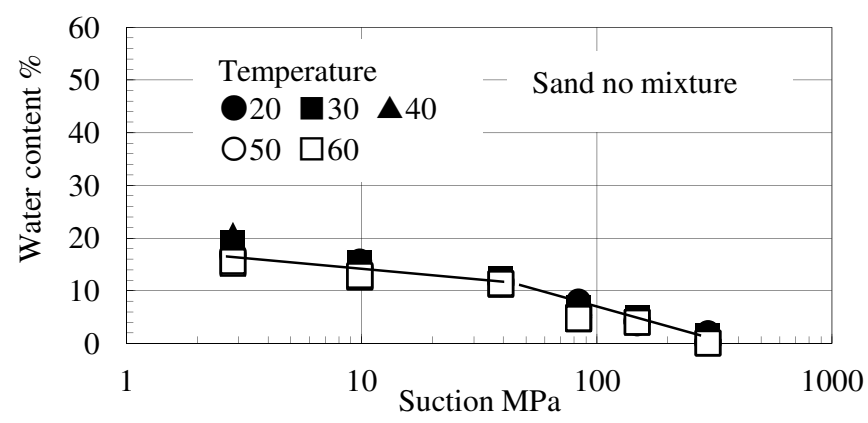

Fig. 1. Reduction of water content with suction.

This study used a modified direct shear apparatus, as shown in Fig. 2(a) (b) (c). The modified direct shear apparatus was possible to keep constant vertical stress, suction and soaking of a specimen, which was developed to evaluate unsaturated-saturated soil behaviour with vertical stress. Also, it is possible to control horizontal shear deformation speed with accuracy, which was from $0.0005 \mathrm{~mm}$ per min to $1.0 \mathrm{~mm}$ per min. Air cylinder supplied a vertical force to the upper face of the specimen. The shear box was placed in the cell chamber, and shear forces induced by horizontal moving of the lower box was measured during the test. Supply of water to the chamber induced that the unsaturated condition changed to saturation due to swelling performance. While specimen produce hydro-saturation, the volume of specimen remained recorded through a strong clamp fixed to a vertical rod attached to the upper surface of the specimen. At least one month was permitted as a period of time for the completely swelling performance. Measured data sets were recorded automatically in a PC.

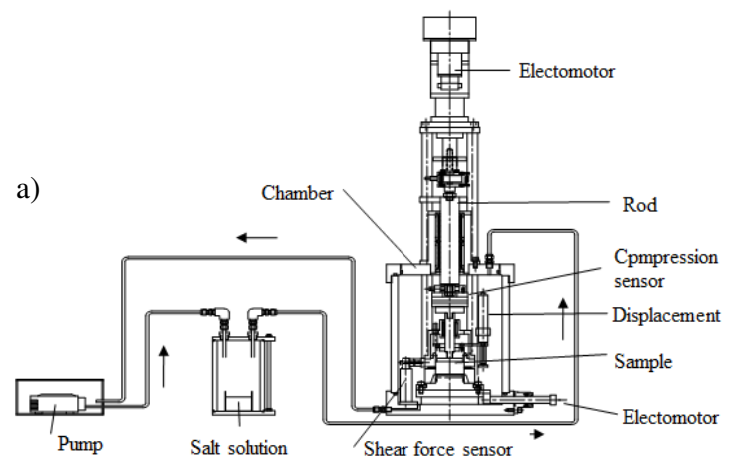

b)

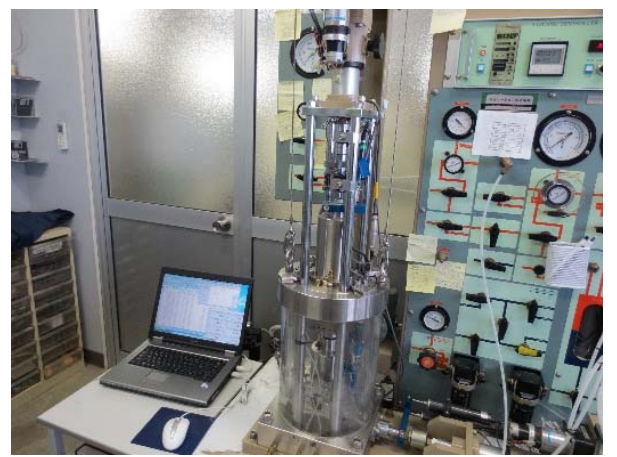

c)

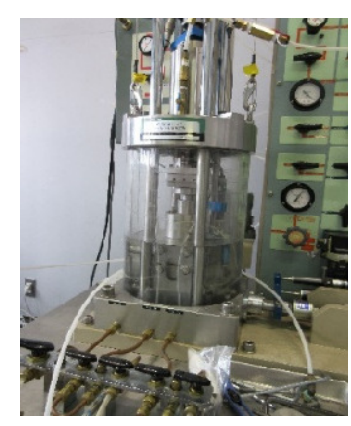

Fig. 2. (a) Schematic of modified direct shear apparatus. (b) A complete view of the direct shear test system. (c) Shear box soaking in cell.

\subsection{Testing program}

The testing program consists of unsaturated soil direct shear test and saturated direct shear test at various horizontal displacement rates. Different net normal stresses and different pore-water pressures were applied to the specimen. Here, it was defined that net normal stress directly applied to the upper surface of the specimen. The net normal stress is not effective stress defined as the difference between confining pressure and excess pore-water pressure. 


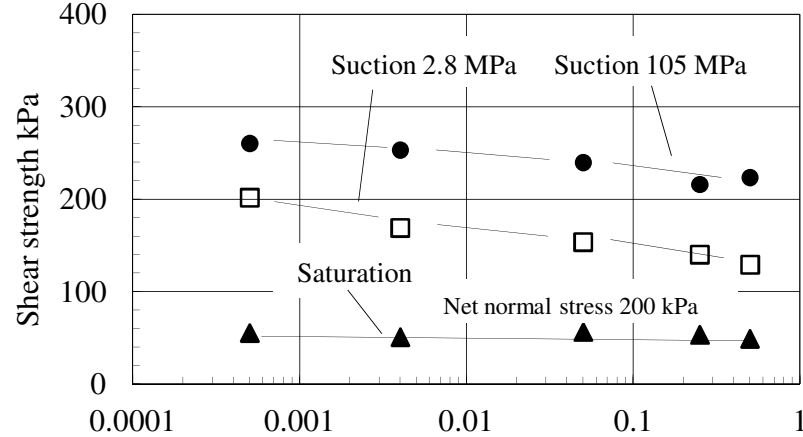

Horizontal displacement rate $\mathrm{mm} / \mathrm{min}$

Fig. 3. Influence of shear rate on shear strength.

Controlled horizontal displacement rate had a range from $0.0005 \mathrm{~mm}$ per min to $0.5 \mathrm{~mm}$ per min till the end of the test. Measured net normal stresses were up to 500 $\mathrm{kPa}$. Added pore-water pressure used to saturated specimens were induced by applying air pressure to the water surface in the chamber. While the specimen had pore-water pressure, the specimen was completely soaked in water. The pore-water pressures ranged from $100 \mathrm{kPa}$ to $400 \mathrm{kPa}$. The maximum value in difference between net normal stress and pore-water pressure (including atmospheric) was $500 \mathrm{kPa}$.

\section{Test results}

\subsection{Shear strength of unsaturated bentonite}

The direct shear test under constant vertical stress of 200 $\mathrm{kPa}$ was conducted out for unsaturated bentonite and saturated bentonite. All specimens were mixed with sand. The bentonite specimens had various suction such as $105 \mathrm{MPa}, 2.8 \mathrm{MPa}$ and $0 \mathrm{MPa}$ (i.e. saturation). The suction of $105 \mathrm{MPa}$ was coincident with initial suction of compacted bentonite, and suction of $2.8 \mathrm{MPa}$ was controlled due to vapour pressure technique using Potassium Sulfate. Potassium Sulfate maintained RH 98 $\%$ and suction of compacted bentonite reduced in void structure. After swelling performance of the compacted bentonite, the saturated bentonite had net normal stress of $200 \mathrm{kPa}$.

The required shear speed range was from $0.0005 \mathrm{~mm}$ per min to $0.5 \mathrm{~mm}$ per min that maximum shear deformation was $8.0 \mathrm{~mm}$. The stress-strain curves (i.e. the relationship between shear stress and horizontal displacement) provided different slopes with a smooth curve under saturated conditions. Bentonite with high suction indicated strong peak at small horizontal deformation. It was clearly for each stress-strain curve to depend on suction value.

The measured three shear strengths under the different suction values were plotted in Fig. 3, which the relationship between shear speed and shear strength with a constant net normal stress of $200 \mathrm{kPa}$. The shear rates plotted in Fig. 3 had a wide range which was from $0.0005 \mathrm{~mm}$ per minute to $0.5 \mathrm{~mm}$ per minute. Changing of shear strength of bentonite with the suction of 105
$\mathrm{MPa}$ is similar to the suction of $2.8 \mathrm{MPa}$, which shear strength slightly decreased with increasing of the shear rate. When shear speed was over $0.05 \mathrm{~mm}$ per minute, the reduction of shear strength was considerable. Thus, it was certainly for compacted bentonite in unsaturated condition that shear speed influenced the shear strength. In fact, there are similar experimental results on unconfined compression test for unsaturated bentonite. Unconfined compressive strength was measured on unsaturated bentonite at a dry density of $1.600 \mathrm{~g} / \mathrm{cm}^{3}$ with water content of $17.2 \%$ [13]. Relationship between compression speed and unconfined compressive strength was shown in Fig. 4, and there was small variation of strength. The specimen was statically compacted without sand mixture at 20 degrees. It was observed that unconfined compressive strength decreased with compression speed within a range from $0.007 \%$ per min to $1.0 \%$ per min. Also, bentonite subjected to heating was measured the shear strength in direct shear test. The relationship between shear speed and strength [14] was reported as shown in Fig. 5.

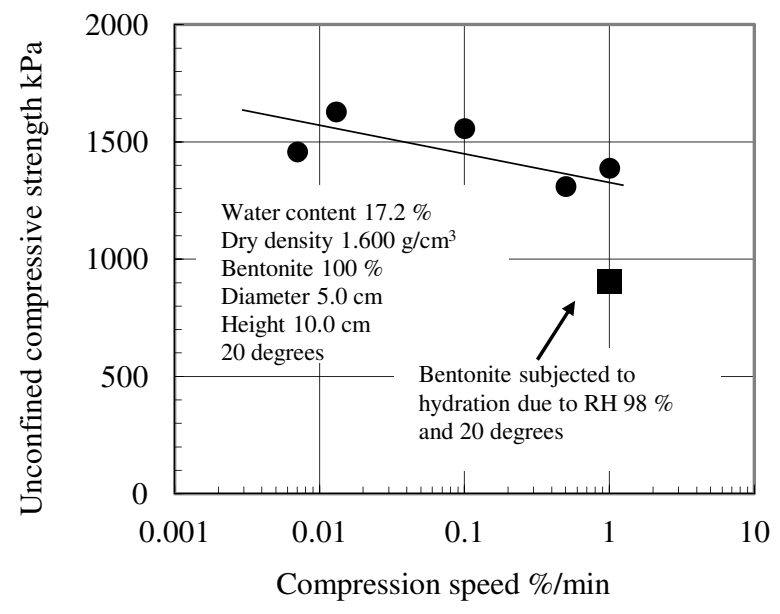

Fig. 4. Reduction of unconfined compressive strength with compression rate for compacted bentonite [13].

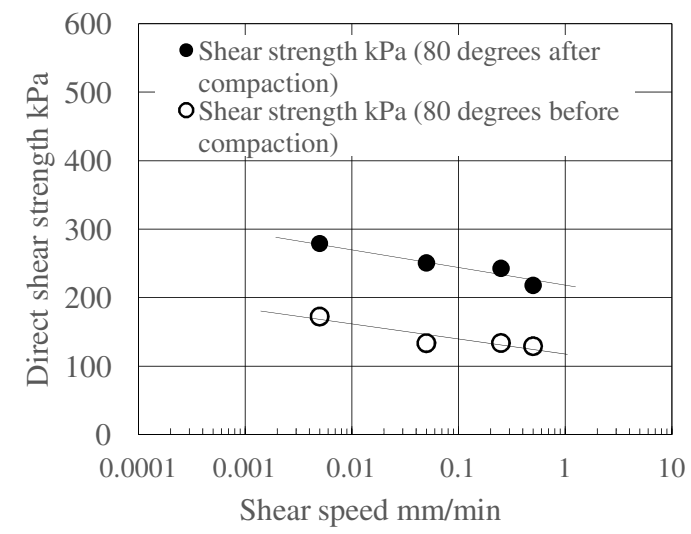

Fig. 5. Effect of shear rate on direct shear strength for bentonite subjected to heating action [14].

In a series of comparative direct shear test using both unsaturated bentonite and saturated bentonite, it was found out appearance different associated with shear speed. The effect of shear speed on shear strength was quite slight for saturated compacted bentonite. In the 
saturated compacted bentonite, the influence of shear speed on the shear resistance was deleted.

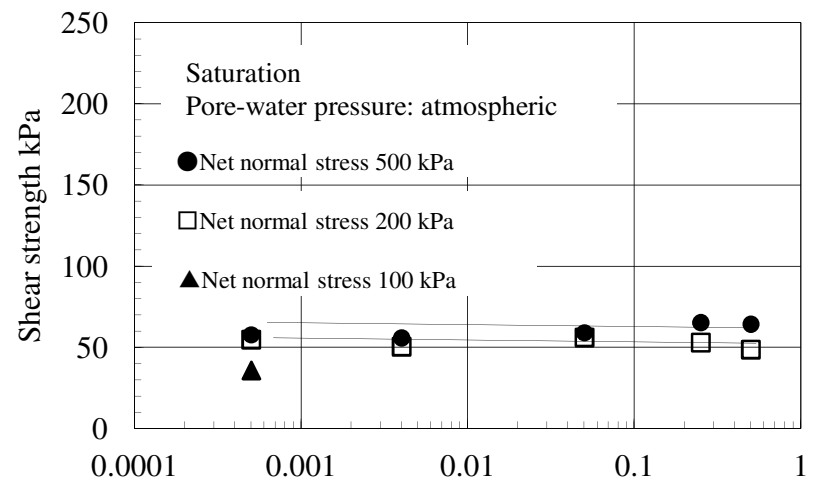

Shear speed $\mathrm{mm} / \mathrm{min}$

Fig. 6. Shear strength of saturated bentonite under pore-water pressure equal to atmospheric.

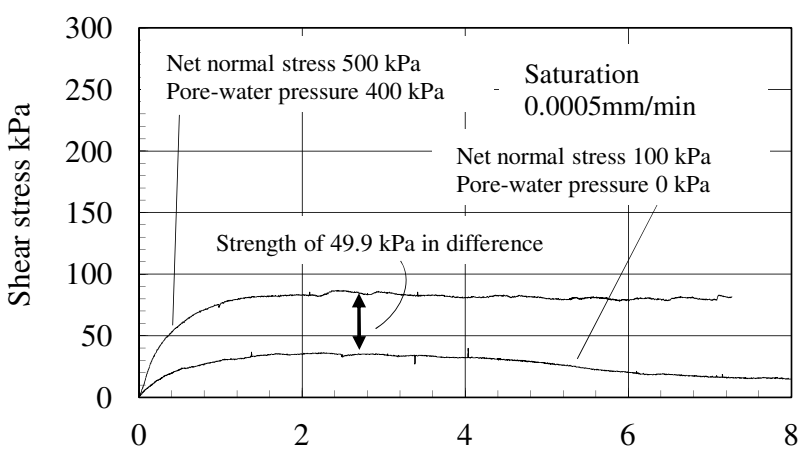

Horizontal displacement $\mathrm{mm}$

Fig. 7. Stress-strain curve for saturated bentonite.

\subsection{Shear strength of saturated bentonite}

The saturated bentonite was tested at three net normal stresses (i.e. $500 \mathrm{kPa}, 200 \mathrm{kPa}$ and $100 \mathrm{kPa}$ ) and shear strengths were measured with some shear speeds. The obtained direct shear strengths were described in Fig. 6 that saturated bentonites having net normal stress of 500 $\mathrm{kPa}$ and $200 \mathrm{kPa}$ remained more than $50 \mathrm{kPa}$ in shear resistance. Also, the influence of net normal stress on shear strength was not so important, and the difference was slightly. It was not explicitly state that increment of shear speed reflected decreasing of shear strength similar to unsaturated bentonite shear properties mentioned in Fig. 3. This testing program had only two net normal stresses (i.e. $500 \mathrm{kPa}$ and $200 \mathrm{kPa}$ ). In addition, $100 \mathrm{kPa}$ was controlled as external loading. The shear strength was $36.1 \mathrm{kPa}$ with a shear speed of $0.0005 \mathrm{~mm}$ per min. There was sufficiently increment of shear strength between $100 \mathrm{kPa}$ and $200 \mathrm{kPa}$. It was observed that some friction effect due to increment net normal stress was produced.

\subsection{Shear strength of saturated bentonite having pore-water pressure}

Pore-water pressure was applied on the saturated bentonite under soaking with air pressure into the chamber of direct shear apparatus induced as excess pore-water pressure. In the case of two different net normal stresses, shear strengths were measured under a shear speed of $0.0005 \mathrm{~mm}$ per min. All specimens were placed into the water during the shear test. Figure 7 indicated stress-strain curves associated with both porewater pressure and zero pore-water pressure for two net normal stresses (i.e. $500 \mathrm{kPa}$ and $100 \mathrm{kPa}$ ). The difference between net normal stress and pore-water pressure was equal to $100 \mathrm{kPa}$. On the saturated bentonite maintained at a pore-water pressure of 400 $\mathrm{kPa}$, the shear stress increased slowly till horizontal displacement was $1.2 \mathrm{~mm}$. Subsequently, saturated bentonite took the residual condition that the shear stress maintained constant value. Then, the evaluated shear strength was almost $80 \mathrm{kPa}$.

Another saturated bentonite was controlled at net normal stress $100 \mathrm{kPa}$, and pore-water pressure was equal to atmospheric. Measured shear stresses were low compare to the above mentioned data sets of net normal stress of $500 \mathrm{kPa}$ and pore-water pressure of $400 \mathrm{kPa}$. Reduction of shear strength was $49.9 \mathrm{kPa}$, as shear strength was $35 \mathrm{kPa}$ for saturated bentonite with a net normal stress of $100 \mathrm{kPa}$ that reduction was more than $100 \%$. The shear strength, however, had changed, and the influence of pore-water pressure on shear strength was recognized certainly.

In case of net normal stress of $500 \mathrm{kPa}$ and porewater pressure of $400 \mathrm{kPa}$, the influence of shear speed on shear strength for saturated bentonite was investigated. Shear speeds were $0.0005 \mathrm{~mm}$ per minute, $0.05 \mathrm{~mm}$ per minute and $0.5 \mathrm{~mm}$ per minute. Measured shear strengths were described as shown in Fig. 8. The saturated bentonite with pore-water pressure of $400 \mathrm{kPa}$ described that shear strength decreased with increment of the shear speed. To apply pore-water pressure produced the effective on shear strength for saturated bentonite. The tendency effectively agrees with the verification mentioned in Fig. 3 for unsaturated bentonite.

Direct shear tests were conducted out for saturated bentonite with pore-water pressure and the difference between net normal stress and pore-water pressure maintained $100 \mathrm{kPa}$. Shearing was maintained under 100 $\mathrm{kPa}$. Figure 9 showed stress-strain curve measured at a shear speed of $0.8 \mathrm{~mm}$ per min till horizontal displacement of $8.0 \mathrm{~mm}$. Two stress-strain curves were almost the same as both shear strength and shear stress under residual condition were coincident. The porewater pressures were $200 \mathrm{kPa}$ and $100 \mathrm{kPa}$. Measured shear strengths were the same under the same difference between net normal stress and pore-water pressure. 


\subsection{Shear strength at $100 \mathrm{kPa}$ difference between net normal stress and pore-water pressure of saturated bentonite}

Shear strengths were summarized for saturated bentonite when the difference between net normal stress and porewater pressure was $100 \mathrm{kPa}$, and data sets were added while pore-water pressure was atmospheric, as shown in Fig. 10. All shear strengths were measured at a shear speed of $0.8 \mathrm{~mm}$ per min. The circle symbol was for an applied pore-water pressure, and the triangle symbol was for atmospheric.

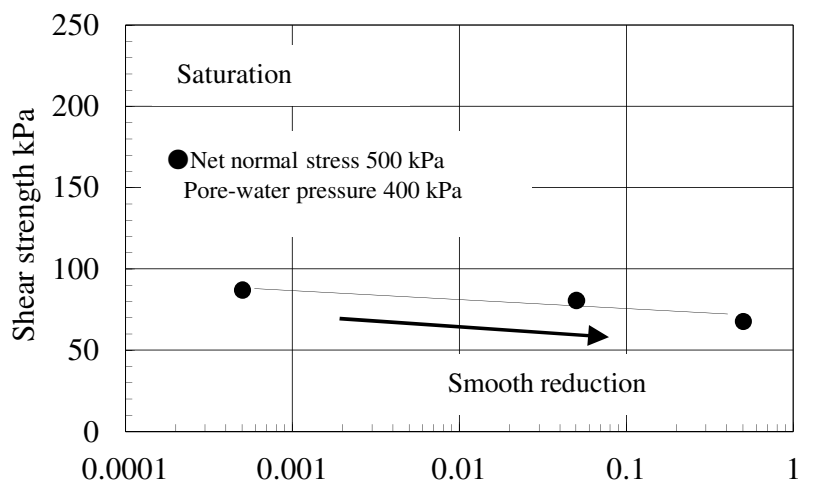

Shear speed $\mathrm{mm} / \mathrm{min}$

Fig.8. Reduction of shear strength with shear speed for saturated bentonite.

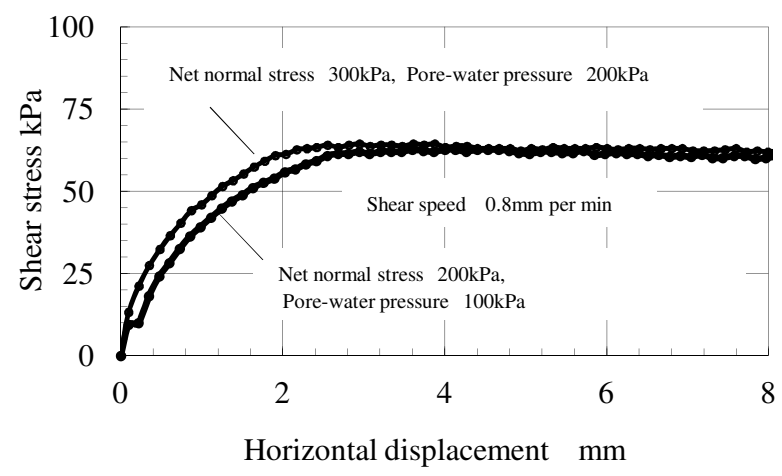

Fig.9. Stress-strain curve when net normal stress and porewater pressure was $100 \mathrm{kPa}$.

In the case of atmospheric pore-water pressure, shear strengths increased smoothly with net normal stress that represents the effect of net normal stress on shear resistance. When net normal stress was $500 \mathrm{kPa}$, shear strength approached $67.6 \mathrm{kPa}$. The saturated bentonite indicated shear strength of $62.4 \mathrm{kPa}$ at net normal stress of $200 \mathrm{kPa}$, and some small influence of pore-water pressure was observed. Beyond a net normal stress of $200 \mathrm{kPa}$ the increment of shear strength was small. Thus, the shear strength increment rate was only $1.7 \%$ to net normal stress, and it was possible to evaluate it as negligible.

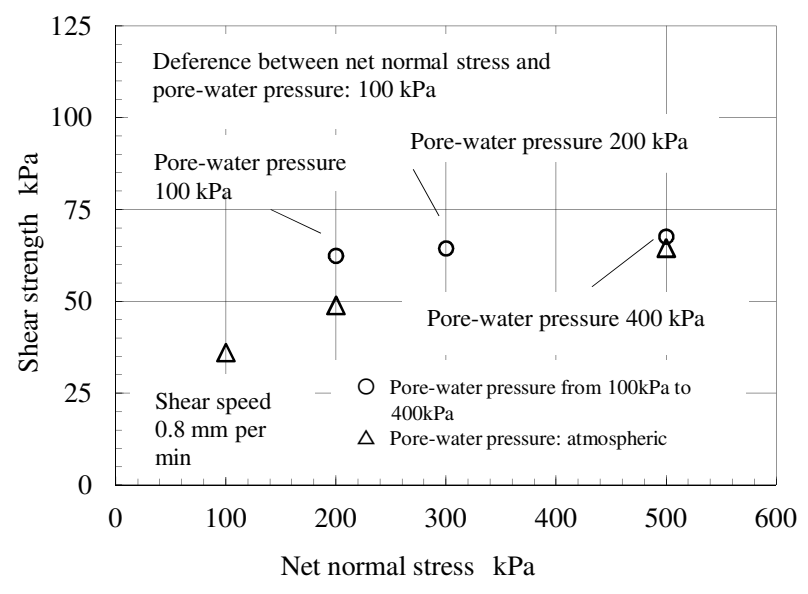

Fig.10. Shear strength for saturated bentonite at various porewater pressures.

\section{Conclusions}

This study was carried out using direct shear tests on a modified direct shear apparatus on both unsaturated bentonite and saturated bentonite at various shear rates. All the bentonite specimens had a sand mixture. The different suctions were obviously changing the shear strength of the unsaturated bentonite. The application of pore-water pressure was observed to be a significant factor in the mechanical properties. The summary of the obtained results are indicated as follows;

(1) Direct shear strength for unsaturated bentonite decreased with decreasing suction. Also, the decrease in shear strength due to saturation was significantly large. Regarding the influence of shear rate, smooth reduction in shear strength was represented that it was similar tendency with previous works results for unsaturated compressive strength properties for compacted bentonite. Shear strength of saturated bentonite associated with various shear speeds was compared to unsaturated bentonite. It was possible to neglect the influence of shear speed on shear strength of saturated bentonite.

(2) Applying pore-water pressure was further effective to shear strength of saturated bentonite. Even if the difference between net normal stress and pore-water pressure was the same, measured shear strengths of saturated bentonite with pore-water pressure equal to atmospheric was smaller compared to that with pore-water pressure higher than atmospheric. It raised inevitably that pore-water pressure was an indispensable strength component for saturated bentonite.

(3) It should not be neglected the effect of shear rate in both unsaturated and saturated bentonites having pore-water pressure more than atmospheric. 


\section{References}

1. A. Gen, B. Vallejan, M. T. Zandrain, M. Sanchez, Homogenization in clay barrier and seals: two case studies, Journal of Rock Mechanics and Geotechnical Engineering, 5, 191-199 (2013)

2. ENRESA, FEBEX Project, Full-scale engineered barriers experiment for a deep geological repository for high level radioactive waste in crystalline host rock, Final Report, Publicación Te'cnica ENRESA 1/2000, Madrid (200).

3. M. V. Villar, First results of suction controlled oedometer test in highly expansive montmorillonite, In: Alonso, E.E., Delage, P. (Eds.), Proc. 1st Int. Conf. on Unsaturated Soils, Paris, vol. 1. Balkema/Presses des Ponts et Chausse'es, 207- 213 (1995).

4. S. Olivella, A. Gens, J. Carrera, E. E. Alonso, Numerical formulation for a simulator (CODEBRIGHT) for the coupled analysis of saline media, Engineering Computations, 13(7), 87-112 (1996)

5. A. Gens, Soil-environment interactions in geotechnical engineering, Geotechnique, 60(1), 6374 (2010)

6. J. O. Lee, J. G. Lim, I. M. Kang, S. Kwon, Swelling pressures of compacted Ca-bentonite, Eng. Geol. 129-130 (2012).

7. M. Ochs, B. Lothenbach, M. Shibata, H. Sato, M. Yui, Sensitivity analysis of radionuclide migration in compacted bentonite: a mechanistic model approach, J. Contam. Hydrol. 61 (1-4), 313-328 (2003)

8. M. V. Villar, P. L. Martín, F. J. Romero, Long-term THM tests reports: THM cells for the HE-E test: update of results until February 2014. PEBS Deliverable 2.2-7.3. Technical Report CIEMAT/DMA/2G210/03/2014. Madrid, 19 (2014)

9. W. M. Ye, M. Wan, B. Chen, Y. J. Cui, J. Wang, Temperature effects on the unsaturated permeability of the densely compacted GMZ01 bentonite under confined conditions, Eng. Geol. 126, 1-7 (2012)

10. Alonso, E.E., Romero, E., Hoffmann, C. and GarciaEscudero. E. (2005). "Expansive bentonite-sand mixtures in cyclic controlled-suction drying and wetting." Engineering Geology, 81, 213-216

11. T. Nishimura, J. Koseki, J. Influence of shear speed on direct shear strength for compacted bentonite with different soil suctions, Third International Conference on Geotechnique, Construction Materials and Environment, Nagoya. Geo-Mate 2013, 598-603 (2013)

12. T. Nishimura, Influence of shear speed on hydromechanical behavior for compacted bentonite, The 15th Asian Regional Conference on Soil Mechanics and Geotechnical Engineering, 15ARC, JPN-051 (2015)

13. T. Nishimura,M. Matsumoto, Influence of thermal heating on unsaturated bentonite strength, The 7th
International Conference on Unsaturated Soils, UNSAT 2018, 609-614 (2018)

14. T. Nishimura, Direct shear strength of heating and hydration bentonite-sand mixture sand, 9th Int. Conf. on Geotechnique, Construction Materials and Environment, (2019) (acceptance) 